\title{
Evaluation of Serum Levels of High-Mobility Group Box 1 Protein in Acne Vulgaris
}

A.A.Ibrahim ${ }^{1}$, R.M.Salem ${ }^{1}$, A.A.Hafez ${ }^{2}$ and H.A.Abd Allah ${ }^{3}$

${ }^{1}$ Dermatology and Andrology Dept., Faculty of Medicine, Benha Univ., Benha, Egypt

${ }^{2}$ Clinical and Chemical Pathology Dept., Faculty of Medicine, Benha Univ., Benha, Egypt

${ }^{3}$ Dermatology Dept., Albehira Hospital, Egypt

E-Mail: Hasnoaa23@gmail.com

\begin{abstract}
Acne vulgaris, is a chronic inflammatory skin disease that occurs when hair follicles are clogged with dead skin cells and oil from the skin .It is characterized by blackheads or whiteheads, pimples, oily skin and possible scarring. The aim of the present study is to evaluate the serum levels of high mobility group box 1 protein [HMGB1] in patients with Acne Vulgaris. This study was carried out on 60 patients suffering from ACNE VULGARIS and 20 apparently healthy individuals of matched age and sex as a control group. Patients were recruited from the outpatient clinic of Dermatology and Andrology Department of Benha University Hospitals during the period from JULY 2018 to DECEMBER 2018. HMGB1 serum levels in acne patients [32.67 \pm 21.53 ] were significantly higher than the levels in control subjects [26.63 \pm 5.77$]$ [ $=0.011]$. Knowledge about early markers such as HMGB1 may facilitate diagnosis of acne disease and monitoring the treatment.
\end{abstract}

Keywords: Andrology, AV, HMGB1and metabolic syndrome.

\section{Introduction}

Acne vulgaris, Is a chronic inflammatory skin disease that occurs when hair follicles are clogged with dead skin cells and oil from the skin .It is characterized by blackheads or whiteheads, pimples, oily skin and possible scarring

It essential influences territories about skin for a moderately helter skelter amount from claiming oil glands, including those face, upper midsection and the over. The coming about presence might prompt anxiety, diminished self-steem What's more to amazing cases, gloom alternately musings of suicide aerial attacker. [1]. Helter skelter portability gathering box-1 [HMGB1] is a very monitored protein Awhile ago known as a DNA-binding protein included On support about nucleosome structure Also regulation from claiming gene transcription, Right away distinguished Concerning illustration a late arbiter for septic stun and also An pro-inflammatory cytokine. [2]. HMGB1 available in the cores What's more cytoplasm for almost every one cell sorts. Because of the opposition to infection, aggravation or injury, HMGB1 may be actively discharged Eventually Tom's perusing intrinsic safe phones Furthermore discharged passively Eventually Tom's perusing harmed or harmed units. There would two pathways clinched alongside which HMGB1 camwood make discharged extracellularly: one may be an dynamic methodology which occurs; when units laid open on incendiary mediators, for example, such that lipopolysaccharide [LPS], tumor putrefaction element [TNF]- $\alpha$, Also interferon [IFN]- $\gamma$; alternate will be An indifferent transform Throughout cell division corruption [2].

Extracellular HMGB1 need been embroiled in the pathogenesis of Different incendiary and immune system sicknesses such as; systemic lupus erythematosus [SLE], rheumatoid joint inflammation [RA] and ankylosing spondylitis [3, 4]. Nonetheless the parts about HMGB1 in the vast majority sorts about incendiary skin sicknesses for example, such that skin inflammation vulgaris [AV] would still not fully caught on [5].

\section{Subjects and methods}

Type of the study is a case control study. This study was carried out on 60 patients suffering from ACNE VULGARIS and 20 apparently healthy individuals of matched age and sex as a control group. Patients were recruited from the outpatient clinic of Dermatology and Andrology Department of Benha University Hospitals during the period from JULY 2018 to DECEMBER 2018.

\subsection{Ethical considerations}

The study was approved by the local ethics committee on research involving human subjects of Benha Faculty of Medicine. Informed consent was obtained from each individual before sample collection.

\subsection{Inclusion criteria}

Patients were included in this study when: Age more than 18 years old, clinically typical acne vulgaris and Different degrees according to severity of acne.

\subsection{Exclusion criteria}

Any subject was excluded from the study if he/ she were: Patient with other skin diseases, Patient with other inflammatory, autoimmune and infectious systemic or cutaneous diseases and Patient on systemic or topical anti acne therapy.

\subsection{Methods \\ All patients were subjected to the followings 2.4.1 Full History Taking}

Personal history: Name, age, sex, occupation, residence, special habits of medical importance and marital status: Present history: Onset, course, duration of urticarial, relation to psychological 
stress, sun exposure and certain foods, Family history of acne vulgaris and Past history: History of medications [Type, dose and duration], and history of other skin diseases.

\subsubsection{Clinical examination}

Dermatologic examination to assess the distribution of acne and the type of the lesions and to exclude other skin diseases.

\subsubsection{Laboratory investigations}

All studied subjects were tested Serum level of HMGB1 using ELISA kits.

\subsection{Sampling}

Five $\mathrm{ml}$ venous blood was collected from each subject by clean venipuncture using disposable plastic syringe. Samples placed on plain tube [without anticoagulant] for serum separation. The tubes were left at room temperature for 30 minutes till coagulation, and then were centrifuged [at 1500 rpm for 15 minutes]. The resultant serum was tested for HMGB1 by standard laboratory method.

\subsection{Statistical Methods}

The collected data was revised, coded, tabulated and analysed with using Statistical package for Social Science [IBM Corp. Released 2011, IBM SPSS Statistics for Windows, and Version 20.0. Armonk, NY: IBM Corp.]. Data were presented and suitable analysis was done according to the type of data obtained for each parameter.

\section{Results and discussion}

\subsection{Results}

Patient and control subjects were matching regarding age, sex and BMI. Age of patints was ranging from 18 to 35 years old.

Data of the studied patients are displayed in Table (1).

The HMGB1 serum levels in acne patients were significantly higher than the levels in control subjects $[\mathrm{p}=0,011]$ Fig $(1,2)$.

Table (1) History and clinical findings in the studied patients

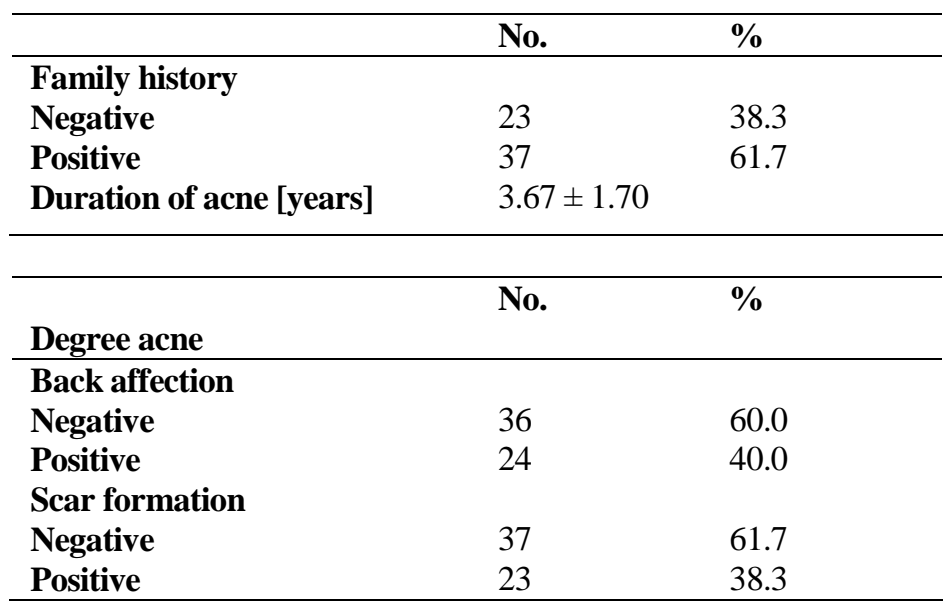

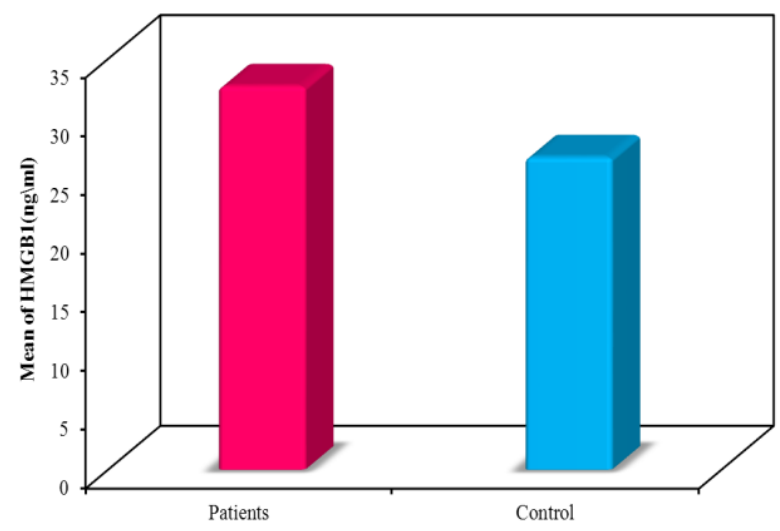

Hmgb1: high mobility group box 1 protien

Fig (1) Comparison between the two studieded groups according to HMGB1. 


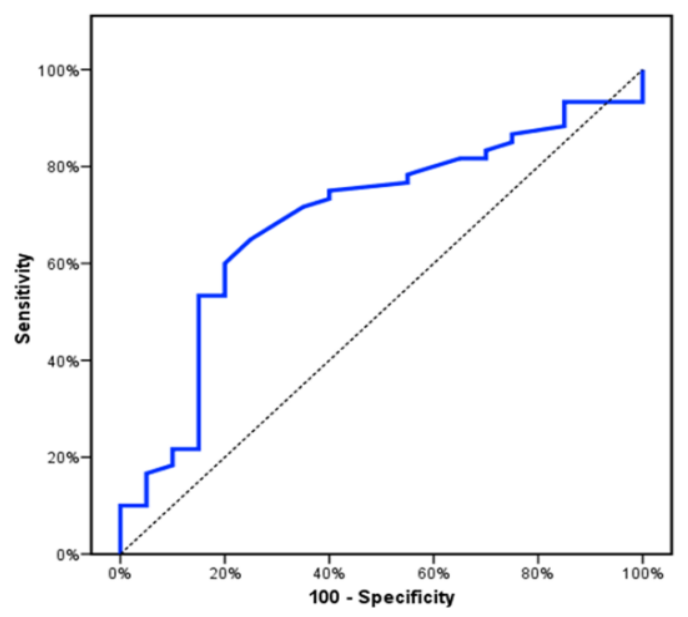

Fig (2) ROC curve for HMGB1to predict patients versus control.

Table (2) Diagnostic performance of HMGB1 in acne

\begin{tabular}{ccccccccc}
\hline & AUC & P & 95\% C.I & Cut off & Sensitivity & Specificity & PPV & NPV \\
\hline HMGB1[ng $\backslash m \mathrm{ml}]$ & 0.691 & $0.011^{*}$ & $0.559-0.523$ & $>25.6$ & 65 & 75 & 88.6 & 41.7 \\
\hline
\end{tabular}

HMGB1: high mobility group box 1 AUC: Area Under a Curve p value: Probability value CI: Confidence Intervals NPV: Negative predictive value PPV: Positive predictive value *: Statistically significant at $\mathrm{p} \leq 0.05$

\subsection{Discussion}

Acne vulgaris is a chronic inflammatory dermatosis of the pilosebaceous units which is characterized by open and/or closed comedones [blackheads and whiteheads] and inflammatory lesions including papules, pustules, or nodules, in some cases, is accompanied by scarring. The etiology of acne appears to be complicated and is not completely understood [6].

Skin inflammation vulgaris is a as a relatable point constant skin infection as, it will be a malady of the pilosebaceous unit (hair follicles in the skin that would connected with an oil gland). The lesions of skin inflammation vulgaris need aid sorted under non-inflammatory lesions (open Also shut comedones), incendiary lesions (papules, pustules, nodules, What's more cysts) [7].

Helter skelter -mobility bunch box 1 [HMGB1] will be An marker of both tissue damage and intrinsic safe reaction [2]. Under physiological conditions, HMGB1 is spotted in the core. When Mobile actuation alternately damage alternately passing occurs, HMGB1 could translocate outside of the cell Also turns into a proinflammatory arbiter [8].

Helter skelter portability aggregation box 1 (HMGB1) is a very monitored protein Awhile ago known as DNA-binding protein included for upkeep for nucleosome structure and regulation for gene transcription, It's discharged from macrophages Concerning illustration An late biomarker of sepsis and also An ace incendiary cytokine. [2]. This prospective body of evidence control examine pointed to assess those serum levels of HMGB1 over patients for skin inflammation vulgaris. In the available study, HMGB1 serum levels over skin break out patients were altogether higher over the levels in control subjects.

Of the best for our knowledge, HMGB1 might have been not assessed to skin break out before, in spite of the fact that it need been viewed as Likewise An pro-inflammatory cytokine in the pathogenesis from claiming Different incendiary Furthermore immune system infections for example, such that psoriasis [9], alopecia areata[10], Bechet sickness [11], rheumatoid joint inflammation [4], ankylosing spondylitis [5] and systemic sclerosis [12].

\section{Conclusion}

The serum levels of HMGB1 are elevated in acne patients. Knowledge about early markers such as HMGB1 may facilitate diagnosis of acne disease, monitoring the treatment, detection of metabolic syndrome in acne patients, and recognizing the impact metabolic syndrome has on the efficacy of acne treatments.

\section{Reference}

[1] A.El-Taweel, R.M.Salem , Q.S.Elshimi, H.E Bayomy, tyoe 1 and type 2 acute phase protiens in acne vulgaris, J E W D S Vol.16.pp .31-36.2019.

[2E.J.Karakike, M.E.Adami, M.Lada, M.Bauer. Late peaks of HMGB1 and sepsis outcome. Cli Sci Aspects, Vol.52, pp. 334-339. 2019.

[3] RS. Goldstein, A. Bruchfeld, L. Yang, Cholinergic Anti-Inflammatory Pathway 
Activity and High Mobility Group Box-1 [HMGB1] Serum Levels in Patients with Rheumatoid Arthritis. Molecular medicine, Vol.13, pp. 210-215, 2007.

[4] DA. Abdulahad, J. Westra, J. Bijzet, High mobility group box 1 [HMGB1] and antiHMGB1 antibodies and their relation to disease characteristics in systemic lupus erythematosus. Arthritis research \& therapy, pp. 13-R71, 2011.

.[5] P. Oktayoglu, S. Em, M. Tahtasiz, Elevated serum levels of high mobility group box protein 1 [HMGB1] in patients with ankylosing spondylitis and its association with disease activity and quality of life. Rheumatology international, Vol.33, pp. 1327-1331, 2013.

[6] Bettoli V, Coutanceou C, Georgescu V. A real life international, observational study demonistrating the efficacy of a cosmetic emulsion in the supportive care of mild to moderate acne. Clin Cosmet Investig Dermatol , Vol.12. Pp.759-769,2019.

[7] Xu X, Zheng Y, Zhao Z, Zhang X, Liu P, Li C. Efficacy of photodynamic therapy combined with minocycline for treatment of moderate to severe fascial acne vulgaris and influence on quality of life. Med; Vol 96. Pp.51, 2017.
[8].Andersson U, Antoine DJ, Tracy KJ, The functions of HMGB1 depend on molecular localization and post translational modifications. J Intern Med; Vol.276 ,pp.420424. 2014.

[9] M. Kamel, E. Hassan, M. Sobhy, Role of highmobility group box-1 as a marker of disease severity and diagnosis of metabolic syndrome in psoriatic patients. Egyptian Journal of Dermatology and Venerology, Vol.37, pp. 69$75,2017$.

[10] Y. Lee, H-E. Lee, J.M. Shin, Clinical significance of serum high-mobility group box 1 level in alopecia areata. Journal of the American Academy of Dermatology, Vol.69, pp. 742-747, 2013.

[11] CGM. Kallenberg, J. Westra, AWS. de Souza, High mobility group box 1 serum levels are increased in Behçet's disease, but not associated with disease activity or disease manifestations. Rheumatology, Vol.54, pp. 2151-2155, 2015.

[12]. A. Yoshizaki, K. Komura, Y. Iwata, Clinical Significance of Serum HMGB1 and SRAGE Levels in Systemic Sclerosis: Association with Disease Severity. Journal of clinical immumology,vol,29,pp.180-189,2009. 